\title{
UNA SEMBLANZA DEL CONQUISTADOR DEL ORIENTE BOLIVIANO: EL ITINERARIO POLÍTICO DE ÑUFLO DE CHAVES (1540-1568)
}

\author{
A Sketch of the Conqueror of the Eastern Bolivia: Nuflo de Chaves' political \\ itinerary (1540-1568)
}

\section{Cecilia G. Martínez*}

\section{Resumen}

A partir de la experiencia de Ñuflo de Chaves entre los años 1540 y 1568, este trabajo ofrece un análisis del proceso de conquista y colonización del oriente boliviano prestando especial atención a los derroteros geográficos y los recorridos políticos por medio de los cuales, en la relación del conquistador con otros españoles -individuos e instituciones-, Chaves logró erigirse como figura de poder. A través del examen de documentos coloniales del virreinato del Perú, de los gobernadores y de los oficiales reales del Río de la Plata y de informaciones de méritos y servicios de los conquistadores, se identifican los elementos que hicieron de la conquista de Santa Cruz de la Sierra un proceso excepcional que permite enunciar principios generales para un tema poco explorado hasta el presente como el de la conquista del oriente boliviano.

$$
<\text { Ñuflo de Chaves }><\text { Oriente boliviano }><\text { conquista }><\text { Santa Cruz de la Sierra }>
$$

\begin{abstract}
Based on Nuflo de Chaves' experiences between 1540 and 1568, the article analyses the process of conquest and colonization of Eastern Bolivia and the geographical paths and political itineraries by which Chaves became a political figure and established meaningful relationships with individual Spaniards and Spanish institutions. Through the examination of colonial documents from the Viceroyalty of Peru, the Governors and Royal Officials of the Río de la Plata and information of the conquerors' merits and services, we identify certain elements that rendered the conquest of Santa Cruz de la Sierra an exceptional process. Besides, this research allows us to establish some general principles for a scarcely studied topic as the conquest of Eastern Bolivia.
\end{abstract}

$<$ Ñuflo de Chaves $><$ Eastern Bolivia $><$ Conquest $><$ Santa Cruz de la Sierra $>$

Recibido: 28/06/2013 // Aceptado: 20/09/2013

\footnotetext{
* Licenciada en Historia - UBA, Becaria Doctoral CONICET, ceciliagmartinez@gmail.com
} 
El 26 de febrero de 1561 Ñuflo de Chaves fundó la ciudad de Santa Cruz de la Sierra. El asentamiento permanente de españoles en esas tierras y el reparto de encomiendas de indios fueron los pilares sobre los que se erigió la colonización del área cruceña. Pero 1561 también marca el final de un recorrido: es la síntesis de los avances y retrocesos de Chaves durante los veinte años de experiencia en América que antecedieron a su llegada al oriente del actual territorio boliviano. La relación construida entre Chaves y otros españoles a lo largo de esas dos décadas se cuenta entre las circunstancias que en algunos casos dinamizaron la marcha del capitán y en otros le impusieron retracción. Este trabajo se dedica a describirlas y analizarlas asumiendo que forman parte de un proceso dinámico, cuya especificidad no emerge del resultado sino que se define en la experiencia previa a la fundación de la ciudad.

Con el término "españoles" nos referimos a un conglomerado de personas e instituciones cuyo rasgo distintivo es su origen ibérico común y su condición de dominadores en el marco de la conquista, en relación con los habitantes nativos de América. Pero al interior de ese gran conjunto de hombres existían subgrupos cuyas identidades se forjaban en torno a los intereses que defendían, a partir de los cuales asumían lógicas de funcionamiento, definían posiciones y llevaban a cabo acciones que los distinguían de otros subgrupos. En la experiencia de Ñuflo de Chaves en el proceso de conquista de Santa Cruz de la Sierra reconocemos la incidencia de los adelantados y gobernadores del Río de la Plata, de los oficiales reales, de otros capitanes, de los virreyes del Perú, de la Audiencia de Charcas, y de la hueste que lo acompañaba en las expediciones. Si todos los hombres que componían esos grupos tenían en común ser conquistadores, lo que los diferenciaba e incluso enfrentaba era estar regidos por ambiciones de riqueza y preeminencia social que componían un escenario de contienda política donde la rivalidad, la ambición y la controversia eran corrientes (Stern, 1992).

En las próximas páginas analizamos el lugar que ocupó cada uno de ellos en relación con la empresa de conquista de la región cruceña. Prestamos especial atención a la trayectoria de sus acciones en la medida en que confluyen con las de Chaves y nos detenemos a ver cómo y en qué medida condicionaron, determinaron, modificaron o frenaron el avance de aquél. A los efectos de ordenar el análisis, resulta apropiado postular la existencia de dos grandes tipos de actores y circunstancias: aquellos que dinamizaron la conquista, y aquellos que obstaculizaron la marcha de Chaves. Dentro del primer tipo, incluimos las situaciones que le permitieron a Nuflo de Chaves erigirse como figura de poder, tanto frente a sus pares como a las autoridades ante las cuales se presentaba. Consideraremos el lugar que ocupó en las expediciones en las que participó, las alianzas estratégicas con y contra otros capitanes, y la conformación de la hueste que lideró. El segundo tipo, está compuesto por personas y situaciones contrarios a los intereses de Chaves que pusieron freno a su avance. Divisiones de la hueste, superposición con entradas desde otros núcleos colonizadores, diferencias de criterios para la asignación de recursos y disputas en torno a concepciones diferentes sobre la conquista, son algunas de las situaciones que consideraremos dentro de esta categoría. 
Una reflexión aparte merece la peculiaridad que ofrece la intervención de las instituciones de gobierno peruanas, tales como los virreyes y la Audiencia de Charcas. Se debe a que se trata de la conquista de un espacio que desde el punto de vista administrativo quedaría sujeto al Virreinato del Perú -y dentro de éste, a la Audiencia de Charcas-, pero que fue producto de la iniciativa surgida en el Río de la Plata: un espacio periférico, aislado de aquel centro de poder colonial. Frente a esa situación los centros de poder peruano fluctuaron entre posiciones algunas veces favorables y otras veces contrarias -y en algunas circunstancias ambas cosas al mismo tiempo-, lo que refleja una ambigüedad detrás de la cual operaban intereses y proyectos que trascendieron las motivaciones y acciones de Chaves y marcaron el devenir de la historia regional.

La ocupación de la región cruceña fue producto de procesos singulares a partir de los cuales Santa Cruz de la Sierra se erigió como un enclave excepcional. Su excepcionalidad radica en tres factores. El primero, es que fue prácticamente el único de avanzada española sobre el oriente boliviano durante buena parte del siglo XVI. El segundo, es que es el único caso de conquista de un territorio puesto bajo la jurisdicción del Perú llevada a cabo por hombres provenientes del Río de la Plata, territorio que, aunque pertenecía formalmente al virreinato, en la práctica operaba más allá de su órbita de poder. El haber sido producto de la iniciativa del núcleo asunceño no es un hecho menor si tenemos en cuenta que la totalidad de las expediciones de conquista española en América del Sur respondieron a las políticas expansivas emanadas del centro de poder virreinal peruano. En tercer lugar, porque se trata de la ocupación de una porción de las tierras bajas que, a diferencia de los territorios que los españoles explotaban, habían quedado al margen de la dominación incaica, y planteaba el desafío de desplegar estrategias de interacción con los indígenas distintas a las conocidas en los Andes. Por eso los elementos que hacen de la conquista de Santa Cruz de la Sierra un ejemplo peculiar a la vez permiten plantear, a partir de la experiencia de Ñuflo de Chaves, ciertos principios de valor genérico para un tema poco explorado hasta el presente como el de la conquista y los conquistadores del oriente boliviano.

Antes de adentrarnos en el tema específico de este artículo y a los efectos de ofrecer un marco cronológico de referencia para el análisis de la relación Chavesespañoles, en las próximas páginas recorremos los principales hitos de la trayectoria de Chaves en América, a fin de presentar los sucesos más importantes en relación con los antecedentes de la conquista de Santa Cruz de la Sierra.

\section{Chaves en América: derrotero de una conquista}

Nuflo de Chaves llegó a las Indias en noviembre de 1540 con la armada de Álvar Núñez Cabeza de Vaca, el nuevo gobernador del Río de la Plata nombrado por el rey, luego de que Pedro de Mendoza, fundador de Buenos Aires en 1536, se viera obligado a regresar a España aquejado por graves problemas de salud. Desde la partida de Pedro de Mendoza en 1537, hasta que Álvar Núñez Cabeza de Vaca se hizo cargo de la gobernación en 1542, Juan de Ayolas y Domingo Martínez de Irala fueron gobernadores del Río de la Plata. El primero jamás regresó de una entrada emprendida 
en 1537 para llegar a la tierra mítica del Candire ${ }^{1}$. Ante su ausencia, el segundo se hizo cargo de la gobernación, despobló formalmente Buenos Aires en 1541 y se trasladó a la villa de Asunción con los hombres que quedaban (Gandía, 1932: 89-90; Finot, 1939: 89; Roulet, 1993: 117-118, 122, 142; Julien, 2008: 21-24², 33-36³).

La armada de Cabeza de Vaca desembarcó a la altura de la Isla de Santa Catalina, en la costa de Brasil, y desde allí él y sus hombres entraron tierra adentro, en dirección este-noreste hacia Asunción atravesando "El campo", una gran extensión de tierra cubierta de bosques y poblada por indios carios. Al llegar al río Paraná, el grupo debió dividirse en dos: Cabeza de Vaca siguió por tierra con parte de la hueste, mientras que los lisiados y los enfermos bajaron por el río Paraná conducidos por Ñuflo de Chaves (Ruy Díaz de Guzmán 1910 [1612] Libro Primero).

Con la llegada del nuevo gobernador y de los refuerzos de hombres y armas, no tardaron en salir expediciones río Paraguay arriba en busca de información acerca de la ubicación de las minas de metales preciosos y del mejor camino para llegar a ellas. Nuflo de Chaves participó de la primera junto con ochenta españoles más a cargo de Irala. Entre octubre de 1542 y marzo o abril de $1543^{4}$ recorrieron 300 leguas con tres navíos. En octubre de 1543 tuvo lugar una nueva expedición por el río Paraguay hacia el norte - esta vez al mando de Cabeza de Vaca- en la que también participó Chaves. En esta oportunidad subieron hasta el Puerto de los Reyes ${ }^{5}$, y desde allí entraron cincuenta leguas al oeste, pero no pudieron seguir avanzando a causa de las inundaciones estacionales. Fue al regreso de esta entrada, en Semana Santa de 1544, cuando los oficiales reales se rebelaron contra Cabeza de Vaca y terminaron con su breve mandato. Lo arrestaron y un año después lo enviaron a España. Unos días más tarde, Chaves trasladó hasta la costa atlántica a Juan de Salazar Espinosa -otrora célebre fundador de Asunción- para sumarlo al grupo de los expulsados (Díaz de Guzmán 1910 [1612]: 59; Gandía, 1932: 212 nota 80).

\footnotetext{
Candire es una de las formas con que los conquistadores se refirieron en los documentos de los siglos XVI y XVII a un lugar mítico asociado con la abundancia de metales preciosos. También lo llamaban reino del Rey Blanco, el Paititi, el Dorado, la tierra de los candires, la Tierra Rica, la Noticia Rica, la Sierra de la Plata. En todos los casos se trata de distintas formas de mencionar uno o varios lugares que los indígenas de los alrededores del río Paraguay situaban al oeste-noroeste. Un trabajo clásico sobre las expediciones españolas en busca de la quimera de los metales -en el que se intentó documentar la existencia de ese mítico lugar- es el de Roberto Levillier (1976). Una revisión exhaustiva sobre la producción documental, historiográfica y antropológica referida a este tema y a las migraciones guaraníes -íntimamente relacionadas-se encuentra en Combès (2011). También Combès y Tyuleneva (eds.) (2011) reunieron artículos y documentos al respecto.

2 Carta de Domingo de Irala a Su Magestad, 1545.

3 Relación del Río de la Plata, 1545 (Anónima).

${ }^{4}$ La Relación de la jornada al norte, 1542-1543 (Julien, 2008: 1-11) recoge el informe de Irala sobre esta expedición. Tomamos este documento como referencia junto con la Carta de Irala a Su Magestad de 1545 (Julien, 2008: 24) dado que, por ser cercanas al momento en que tuvo lugar la expedición, parecen ser más precisas que las provistas por Chaves. Según este último en su Información de servicios de 1561, la entrada en cuestión tuvo lugar en octubre de 1541 (Julien, 2008: 75).

${ }^{5}$ El Puerto de los Reyes fue fundado en el Pantanal, curso alto del río Paraguay, en la expedición de 15421543 (Julien, 2008: 1).
} 
Con la destitución de Cabeza de Vaca, Irala fue electo gobernador. A partir de entonces se organizaron expediciones hacia el norte y el oeste con el propósito de dar con el camino que condujera a la tierra rica. En octubre de 1545 Chaves formó parte de una entrada por el río Paraguay arriba y tierra adentro, que intentó incursionar por el camino que había seguido Juan de Ayolas, y llegó a los mbayaes ${ }^{6}$. A principios de 1547 el gobernador y los oficiales reales del Río de la Plata acordaron realizar una entrada por el río Aracoay -Pilcomayo- hacia el oeste, que quedó a cargo de Chaves. A fines del mismo año Irala, Chaves y otros españoles volvieron a salir por el río Paraguay, llegaron hasta Itatin y luego se dirigieron tierra adentro hacia el oeste, hasta llegar a la tierra de los tamaguacíes ${ }^{7}$, que habitaban en el piedemonte andino. Allí se encontraron con indígenas que hablaban español, y supieron que esa tierra ya estaba conquistada por blancos que habían llegado desde Perú. Entonces cayeron en la cuenta de que habían logrado comunicar el Río de la Plata con las tierras andinas, por lo que Irala decidió enviar a Chaves a la Ciudad de los Reyes como embajador ante el licenciado La Gasca. Iba encargado de dar cuenta del camino que habían recorrido, ponerse a disposición del virrey, pedir ayuda - provisiones y refuerzos de hombres- y solicitar que se nombrara un gobernador para las tierras que tenían pobladas. Irala y el resto de la hueste esperaría a Chaves en los Gorgotoquíes, unas 30 leguas al este. Pero antes de que regresara los oficiales reales que iban en la expedición se rebelaron contra Irala, nombraron un nuevo líder y gobernador -Gonzalo de Mendoza- y decidieron adelantar el regreso a Asunción (Gandía, 1932: 243-245; Irala 1962 [1555]: 276-282; Levillier, 1976: 210-211).

Al llegar a la Ciudad de Los Reyes, Chaves fue recibido por el licenciado La Gasca, quien nombró como gobernador de Paraguay a Diego Centeno - un encomendero del Alto Perú-, aunque éste nunca ejercería el cargo. Hacía pocos años que había concluido la pacificación del Perú luego de las guerras civiles y del levantamiento de Gonzalo Pizarro. La Gasca temía que la presencia del grupo de hombres llegados desde Asunción provocara nuevos disturbios, por eso los envió de regreso con algunos españoles para poblar Asunción, respondiendo a la demanda de ayuda de Chaves pero además aprovechando la ocasión para descargar la tierra (Levillier, 1921: 136-1618, 168-19099; Julien 2008: 8210; Ruy Díaz de Guzmán 1910 [1612] : 63-64, 67; Finot, 1939: 101).

\footnotetext{
6 Mbayá es un término guaraní aplicado a grupos de indígenas que hablaban lengua guaycurú y que vivían Chaco adentro en dirección al norte desde Asunción (Combès, 2010: 194-195).

7 En los documentos redactados por Irala, Chaves, Salazar y otros españoles que recorrieron la zona el nombre de los grupos étnicos con las que se encontraban son utilizados indistintamente como etnónimos y como topónimos. Los tamaguaciés son los que más aparecen, junto con los gorgotoquíes. Los primeros, también conocidos como tamacoci, tomacoci, tamagoci, tomaguacíes - entre otros-, habitaban las tierras circundantes del río Guapay en la región también conocida como "llanos de Grigotá" (Combés, 2010: 271-279). Gorgotoquíes por su parte designaba a los que vivían donde Chaves fundó Santa Cruz la vieja. (Combès, 2010: 149-155)

${ }^{8}$ Carta del Licenciado La Gasca al Consejo de Indias, Lima, enero de 1549.

9 Carta del Licenciado La Gasca al Consejo de Indias, Lima, mayo de 1549.

${ }^{10}$ Información de Servicios de Ñuflo de Chaves, Santa Cruz de la Sierra, 1561.
} 
Mientras tanto, en Asunción, Diego de Abreu -partidario de Cabeza de Vaca en 1544- aprovechó la ausencia de Irala y organizó un golpe contra el teniente de gobernador Francisco de Mendoza: lo mató y se hizo elegir gobernador. Irala no tardó en ser restaurado en su cargo por quienes lo habían destituído en Tamaguacíes y de regreso a Paraguay desbarató el golpe de Abreu. Cuando Chaves llegó a Asunción un tiempo después, persiguió a Diego de Abreu y sumó al bando iralista a los hombres de Perú que se habían incorporado a su hueste.

En agosto de 1551, llegaron provisiones para la gobernación del Río de la Plata a favor de Diego de Sanabria. Con la armada de Sanabria, Hernando de Salazar llegó a Asunción, y en poco tiempo se convirtió en el nuevo socio de Chaves (Julien, 2008: $\left.120^{11}\right)$.

La siguiente entrada organizada con el objetivo de llegar al Candire tuvo lugar en febrero de 1553. Irala, Chaves y Salazar remontaron el río Paraguay hasta el puerto de San Fernando y desde allí se dirigieron tierra adentro. Nuevamente las ciénagas y pantanos estacionales impidieron su avance, y a ello debió esa expedición el nombre de Mala Entrada que le dieron los contemporáneos (Díaz de Guzmán 1910 [1612]: 69-71; Julien, 2008: $66-69^{12}$ y $\left.70-93^{13}\right)$.

Finalmente a principios de 1558 , los oficiales reales, el gobernador y demás vecinos del Río de la Plata decidieron una nueva entrada a los Xarayes ${ }^{14}$ a cargo de Chaves. Éste aportó a la empresa 23 bergantines y contó con la participación de Hernando de Salazar, que también colaboró con otros dos navíos, armas y caballos. Salieron desde Asunción con el mandato de poblar los Xarayes, pero los expedicionarios siguieron camino hacia el oeste. El ataque de los indios chiquitos ${ }^{15}$ desató conflictos al interior de la hueste que terminó dividiéndose: en julio de 1559 entre 70 y 90 españoles regresaron a Asunción, mientras el resto siguió hasta los Tamaguacíes donde el 1 de agosto de 1559 Nuflo de Chaves fundó Nuestra Señora de la Nueva Asunción -luego conocida como La Barranca. La intención de la fundación era contar con una posta donde prepararse y aprovisionarse para seguir camino hasta el Candire, pero a poco de fundada la ciudad tuvo lugar el encuentro entre los hombres de Chaves con el capitán Andrés Manso, que

\footnotetext{
${ }^{11}$ Información de servicios de Hernando de Salazar, Santa Cruz de la Sierra, 1561-1562.

${ }^{12}$ Relación de los casos en que el capitán Ñuflo de Chaves a servido a Su Magestad desde el año de quinientos y quarenta, Santa Cruz de la Sierra, 1561.

${ }^{13}$ Información de servicios de Ñuflo de Chaves, Santa Cruz de la Sierra, 1561.

14 "Xarayes" o "xarays" es el nombre que le daban a los indígenas que poblaban el curso alto del río Paraguay, conocido también como Pantanal porque discurre entre marismas.

15 "Chiquito" es la traducción de tapuy miri, término utilizado por los guaraníes que acompañaban a los conquistadores del Paraguay para nombrar a unos indígenas que vivían tierra adentro al oeste del Pantanal, que se caracterizaban -y eran temidos- por usar flechas envenenadas. Según distintas interpretaciones tapuy miri significa "siervos chicos" o "chozas chicas". El calificativo chico - del que deriva el etnónimo "chiquito"- hace referencia al tamaño que tenían sus casas para evitar la entrada de mosquitos (Métraux, 1942; Susnik, 1978; Combés, 2010).
} 
llegaba desde Charcas con el mandato de poblar el piedemonte lindero para frenar los ataques de los chiriguanos ${ }^{16}$ (Julien, 2008: 72 y 78 ${ }^{17}$; Finot, 1939: 165-167).

Dado el conflicto sobre a quién correspondía el mérito de la conquista de esas tierras, decidieron que Chaves y Hernando de Salazar fueran a la Ciudad de Los Reyes para dirimirlo ante las autoridades virreinales, mientras Manso los esperaba en Nueva Asunción. La ausencia de Chaves y Salazar duró un poco menos de un año: desde agosto de 1559 hasta julio de 1560. En el camino de regreso, a la altura de Pojo recibieron noticias del levantamiento de Andrés Manso, que se negaba a acatar las provisiones que llevaba Chaves, según las cuales éste quedaba habilitado para poblar la gobernación de Mojos $^{18}$ en razón del cargo que le otorgó el virrey Andrés Hurtado de Mendoza, Marqués de Cañete. Si bien García Hurtado de Mendoza, hijo del virrey, era formalmente el gobernador, Chaves, su teniente, gobernaría en su ausencia y Hernando de Salazar, alguacil mayor, era quien seguía en la línea sucesoria (Julien, 2008: 64-65 ${ }^{19}$, $\left.78^{20}, 110^{21}\right)$.

A pesar de la resistencia que opuso a la resolución del conflicto con Chaves, Manso fue apresado y llevado a Charcas para ser juzgado. Ñuflo de Chaves, por su parte, fundó Santa Cruz de la Sierra el 26 de febrero de 1561, y en abril del mismo año repartió las encomiendas de indios entre los vecinos. Para entonces, circulaban noticias de la huida de Manso de la cárcel de Charcas, de su entrada a los llanos a la altura del río Parapetí, y su alianza con los chiriguanos de Condorillo ${ }^{22}$, junto a quienes capturaba

16 "Chiriguano" es la versión castellanizada del término "chiriguana" usada a partir del siglo XVII para designar a un grupo particular de migrantes guaraníes, asentados en el piedemonte andino, entre los ríos Pilcomayo y Guapay. Sin embargo, inicialmente, en las fuentes de los españoles de Asunción el término "chiriguano" tuvo un sentido genérico, ya que se utilizó como sinónimo de guaraní o cario, o sea, para designar a cualquier guaraní-hablante. Luego se restringió su uso al grupo asentado en la parte del piedemonte, haciendo las veces de topónimo: Cordillera Chiriguana (Combés, 2010). En este trabajo usamos chiriguanos -la versión castellanizada- para referirnos al grupo de la cordillera.

${ }^{17}$ Información de servicios de Nuflo de Chaves, Santa Cruz de la Sierra, 1561.

${ }^{18}$ Esta gobernación del siglo XVI referida como "poblazón de Mojos" o "provincia y gobernación de los Mojos" en los documentos (en las Provisiones Reales del Marqués de Cañete a favor de Hernando Salazar, Lima, 1560 y en la Provisión Real del Marqués de Cañete nombrando a Nuflo de Chavez como teniente general de la Provincia de Mojos, Lima, 1560 en Julien 2008: 45 y 64, respectivamente) es una jurisdicción creada por el virrey Marqués de Cañete en 1560 a partir de la noticia de la expedición de Nuflo de Chaves. Es distinta de la gobernación militar de Mojos creada en el marco de las reformas borbónicas de fines del siglo XVIII que sólo comprendía la región de las ex misiones jesuíticas de los llanos de Mojos. Aunque los límites de la gobernación de Mojos quinientista son imprecisos, está claro que abarcaba el territorio que se extendía al este del piedemonte andino a la altura latitudinal de Charcas, y que incluía la ciudad de Santa Cruz la vieja. En la era borbónica este territorio más meridional que el de la gobernación militar de Mojos correspondía a la gobernación militar de Chiquitos.

${ }^{19}$ Relación de los casos en que el capitán Ñuflo de Chaves a servido a su Magestad desde el año de quinientos y quarenta, Santa Cruz de la Sierra, 1561.

${ }^{20}$ Información de servicios de Ñuflo de Chaves, Santa Cruz de la Sierra, 1561.

21 Documentos referentes a la fundación de Santa Cruz de la Sierra, Lima, 1561.

${ }^{22}$ Entre los guaraní-hablantes que migraron desde Paraguay hacia el oeste, se distinguen varios grupos. Mientras los que se asentaron al este y noreste de Santa Cruz la Vieja (los itatines) pronto fueron designados como "guarayos", el nombre "chiriguanaes" -castellanizado en chiriguanos - se siguió utilizando para hacer referencia a los grupos de la cordillera. Entre ellos los españoles distinguían a los 
Martínez. Una Semblanza del Conquistador del Oriente Boliviano...

indígenas chané. Pero en 1563 la Audiencia de Charcas redactó una carta al rey en la que le informaba que ambos capitanes, Chaves y Manso, habían asistido a una reunión y acordado la paz. Probablemente fue ese acuerdo el que decidió a Chaves a ausentarse de Santa Cruz durante casi un año: entre 1564 y 1565 regresó a Asunción a buscar a su familia, a la cual había dejado en Paraguay seis años atrás, cuando partió a poblar los Xarayes (Ruy Díaz de Guzmán 1910 [1612]: 96²3).

Desde un tiempo antes de la llegada de Chaves a Asunción, los vecinos del Río de la Plata planeaban viajar al Perú para entrevistarse con las autoridades virreinales. Con la noticia del regreso de Chaves resolvieron que el gobernador Francisco Ortiz de Vergara, el obispo La Torre y el factor Pedro de Orantes, acompañados de un grupo de aproximadamente 100 hombres, viajarían con él a Santa Cruz y luego a Perú. Durante los meses que Chaves se ausentó de Santa Cruz de la Sierra, Hernando de Salazar realizó expediciones defensivas y ofensivas contra diferentes grupos nativos de los alrededores de la ciudad. Para esa época (1564) tuvo lugar el ataque y destrucción de La Barranca por parte de los chiriguanos y la muerte de Andrés Manso en los llanos que desde hacía unos años llevaban su nombre. Al llegar Chaves a Santa Cruz de la Sierra, los asunceños fueron retenidos en esa ciudad mientras el capitán y el factor Orantes partían hacia Charcas con noticias sobre la visita de las autoridades del Río de la Plata (Julien, 2008: 176, 184, 188, 190, 199, 202, 20924).

Entre 1565 y 1566 Chaves condujo una nueva entrada contra los chiriguanos y viajó nuevamente a Charcas, para pedir bastimentos para enfrentar los ataques de los chiriguanos y otros indios aliados que no cesaban de amenazar con atacar Santa Cruz. De regreso a la ciudad - estimamos que a fines de 1566-, Chaves organizó nuevas expediciones contra los chiriguanos de la cordillera, que seguían levantados y aliados con otros pueblos de los alrededores. Los asunceños retenidos en Santa Cruz ya habían partido a La Plata, donde Francisco Ortiz de Vergara fue detenido y desplazado de la gobernación del Río de la Plata. En su lugar fue nombrado Juan Ortiz de Zárate, encomendero de Charcas. Resuelto el problema de la gobernación rioplatense, los de Asunción iniciaron el retorno haciendo escala en Santa Cruz de la Sierra, desde donde Chaves los acompañaría con dos propósitos adicionales: realizar una exploración de ciertos yacimientos mineros, y pacificar a los chiriguanos de Itatín, que al igual que la mayoría de los pueblos de la región se encontraban rebelados. Fue entonces, en 1568, cuando Chaves murió a manos del cacique principal de los itatines, que luego de darle la

del norte, próximos al río Guapay, que formaban la "provincia" de Vitupué, y los de Condorillo, cercanos al río Parapetí (Combés, 2010: 136)

${ }^{23}$ Sobre el regreso de Chaves a Asunción véase también GGV 90/1388.5: 39-40, Diez cartas de la Audiencia de Charcas al Rey, La Plata, 1561-1567 y GGV 91/1440.1: 7-8, Carta del Cabildo de la Asunción del Paraguay, fecha 2 de octubre 1564, sobre los sucesos ocurridos en el Río de la Plata, Asunción, 1564.

${ }^{24}$ Copia de la información de Servicios de Hernando de Salazar, Santa Cruz de la Sierra, 1568. Al respecto véase también Diez cartas de la Audiencia de Charcas al Rey, La Plata, 1561-1567 en Colección Gaspar García Viñas de la Biblioteca Nacional (en adelante GGV), 90/1388.8. 


\section{Mapa de ubicación general}

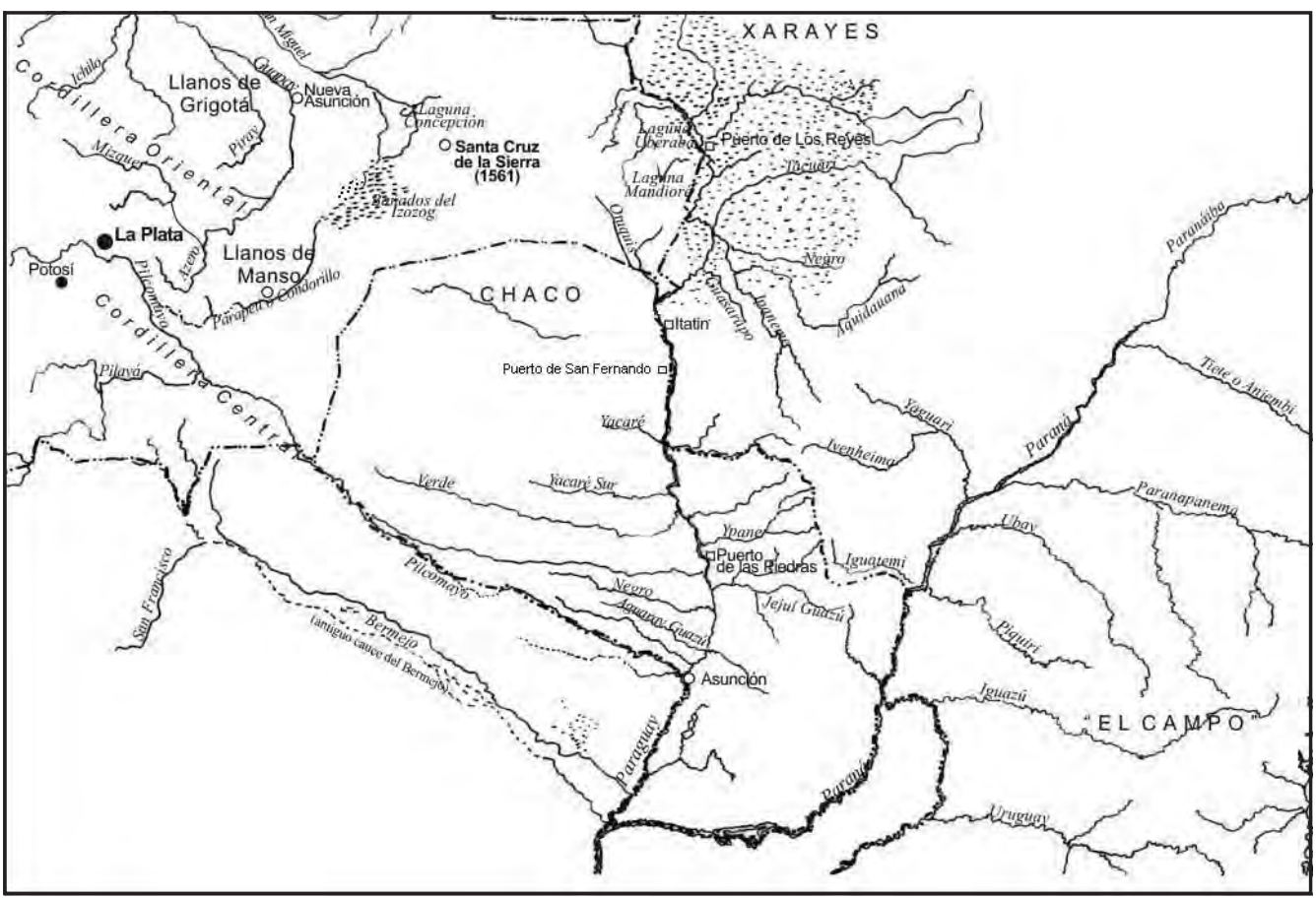

Fuente: Elaborado propia sobre la base de Roulet, 1993: 40-41

bienvenida a su pueblo y ofrecerle lugar para descansar lo mató de un golpe en la cabeza (Julien 2008: 271²5; Ruy Díaz de Guzmán 1910 [1612]: 100).

La experiencia acumulada a lo largo de los veinte años que transcurrieron entre la llegada de Chaves a Asunción y su asentamiento en la Santa Cruz la vieja, fueron trazando un derrotero en el cual circunstancias favorables y adversas se entrecruzaron y delinearon la destreza política y el pragmatismo manifiestos en la fundación de Nuestra Señora de la Nueva Asunción y de Santa Cruz de la Sierra, en el conflicto con Andrés Manso y en las gestiones ante el virrey del Perú y la Audiencia de Charcas. En las páginas que siguen desglosamos las personas y situaciones que entendemos son más relevantes a la hora de analizar la dinámica de la conquista de Santa Cruz de la Sierra a partir de la figura de Nuflo de Chaves y las clasificaremos en las dos categorías que anticipamos en la introducción al presente artículo: lo que motorizó la conquista y aquello que le puso obstáculos a la marcha de Chaves. Como también adelantamos, la Audiencia de Charcas y los virreyes del Perú merecen una mención aparte, no sólo por no ofrecer ejemplos de posiciones enteramente dinamizadoras u obstaculizadoras de la conquista, sino porque además nos permitirán pensar en las particularidades que revistió la nueva gobernación en cuestión y el escenario más amplio al cual quedó incorporada.

\footnotetext{
${ }^{25}$ Relación de los servicios de Nuflo de Chaves y Alvaro de Chaves, La Plata, 1588-1589.
} 


\section{La quimera del Candire. Un proyecto de conquista para los asunceños}

En pocas oportunidades Nuflo de Chaves es mencionado en los documentos del Río de la Plata en la primera mitad de la década del '40 del siglo XVI. Sin embargo, el cruce con las informaciones de servicios que presentó ante las autoridades virreinales a principios de la década de 1560 nos permite inferir el lugar destacado que ocupó en la armada de Cabeza de Vaca. Un primer indicio del incipiente liderazgo que asumió Chaves en su primera experiencia en Indias fue la decisión de este último de despachar por el río con Chaves enfermos e impedidos en el camino desde la costa de Brasil a Asunción. Esas aptitudes para la conducción no pasaron desapercibidas para los españoles que se encontraban en Asunción en el momento en que Chaves arribó a la ciudad. Veinte años después uno de los testigos de su información de servicios, el capitán Bartolomé de Moya, recordaría que "estava ya en la çibdad de la Açençion quando llego el dicho Nufrio de Chaues con el dicho Cabeça de Baca al Rio de la Plata, [...] y que le vido este testigo entrar en la çibdad de la Açençion por cavdillo ${ }^{26}$ de toda aquella jente que traya" (Julien, 2008: $86^{27}$ ). Ambos datos nos permiten imaginar que desde el inicio de su experiencia en América, Chaves contaba con un perfil prometedor para la conquista.

Irala condujo la primera entrada por el río Paraguay en la que Chaves participó entre fines de 1542 y principios de 1543. Recogieron información entre los nativos de la costa del río acerca de las tierras del Candire y del mejor camino para llegar ahí (Julien, 2008: 1-1128). Para Chaves se trató de la primera experiencia de exploración en tierras rioplatenses, y sin duda debió dejarle una marca importante. Por un lado, porque la información recogida entre los pobladores de las orillas del Paraguay sobre el reino del Rey Blanco y del Paititi como fuentes de metales preciosos debió forjar una imagen de la tierra transchaqueña que motivaría las expediciones venideras y se materializaría en la fundación de Nueva Asunción y Santa Cruz de la Sierra, inicialmente pensadas como "postas" en el camino al Candire. Por otra parte, porque la participación en una expedición conducida por Irala debió ser el puntapié de la sociedad que ambos conformarían en los años siguientes para la empresa de exploración y conquista.

Por eso, que Chaves hubiera llegado a Indias en la armada de Cabeza de Vaca no fue obstáculo para que se plegara al bando contrario al gobernador en el levantamiento de los comuneros de $1544^{29}$. Aunque es difícil afirmar la participación de Chaves en

\footnotetext{
${ }^{26}$ Énfasis agregado. Según el Tesoro de la Lengua Castellana o Española de Sebastián de Covarrubias "Caudillo: significa el guiador de la hueste quasi cabdillo, a capite de donde tamnien se dixo capitán, que significa lo mesmo uel caudillo, quasi cavens alium, porque ha de cuidar de toda su gente. De las cualidades del que ha de ser cabdillo habla la ley 4, tit. 23, par. 2, y dize allí la glossa de Montalvo, verbo cabdillos: Assumatur talis in ducem guerrae qui scintiam el intellectum hablat, hoc officium exercendi. Acaudillar, capitanear gente de guerra" (1943 [1611]: 321. Subrayado en el original).

${ }^{27}$ Información de servicios de Ñuflo de Chavez, Santa Cruz de la Sierra, 1561

${ }^{28}$ Relación de la jornada al norte, Paraguay, 1542-1543.

${ }^{29}$ Las denominaciones de "comuneros", con la cual se suele referir a la facción iralista en la gobernación del Río de la Plata (Gandía, 1932; Roulet, 1993), y de "leales", con la que se identifica a los partidarios de Cabeza de Vaca, son una traspolación de los bandos que se enfrentaron en España a principios de la década del 20 del siglo XVI en contra y a favor -respectivamente- de la llegada al trono de Carlos I de España y Emperador Carlos V (Elliott, 1983).
} 
la organización del golpe de Semana Santa de 1544 (Levillier, 1915: 244³0; Díaz de Guzmán [1612] 1910: 57) ${ }^{31}$, no quedan dudas de su adhesión a la facción iralista una vez que Cabeza de Vaca fue arrestado e Irala electo gobernador. Cuando Juan de Salazar Espinosa -alineado con el gobernador depuesto- fue detenido luego de intentar hacer valer un poder firmado por Cabeza de Vaca a su favor para asumir la gobernación del Río de la Plata en 1545, fue Chaves quien salió de Asunción en busca de las naves que llevaban a Cabeza de Vaca a España para sumarlo al grupo de los desterrados. El posicionamiento de Chaves en la facción rebelde tuvo lugar en concomitancia con la construcción de una alianza societaria con Irala a partir de la cual asumiría un papel relevante en las exploraciones del río Paraguay y del Chaco.

A partir de 1545 la evidencia se vuelve más clara. En la nueva expedición organizada "en demanda de la tierra rrica", Chaves participó "con çiento y setenta españoles, y Domingo de Yrala, su theniente, con dozientos y veynte españoles [...] entro a su costa con ochenta arcabuzeros a pie [...] y descubrio la jeneraçion maya, [...] y tomo rrelaçion de la tierra" (Julien, 2008: 66-6732). También a principios de 1547, con el acuerdo del cabildo de Asunción y de los oficiales reales, quedó a cargo de la conducción de una entrada por el río Pilcomayo; y a fines de ese año salió nuevamente con Irala por el río Paraguay arriba y tierra adentro desde el Puerto de San Fernando, llegando al piedemonte andino. Desde ahí emprendió el viaje a la capital virreinal del Perú para entrevistarse con La Gasca. La tarea delegada en Chaves resulta significativa en varios sentidos. Por un lado, porque confirma el lugar relevante que ocupaba en el escenario político del Río de la Plata. En segundo término porque entendemos que el acceso al diálogo y la negociación con los centros de poder pudo haber implicado para Irala asumir el riesgo de ser traicionado, y por eso debemos entenderla en el marco de una sociedad entre Irala y Chaves. Por último, porque esta experiencia sería capitalizada diez años más tarde, al entrevistarse con el virrey Marqués de Cañete a propósito de la gobernación de Mojos. El resultado de la gestión de Chaves en Perú fue el nombramiento de Diego Centeno como gobernador del Paraguay. Además, según consta en su información de servicios, volvió del Perú con su hueste acrecentada por ochenta hombres. Al llegar a Asunción encontró la ciudad desasosegada por el levantamiento de Diego de Abreu; salió en su persecución y lo capturó, con la ayuda de ochenta hombres (Julien, 2008: 76-7733). Su disposición para el arresto de Abreu y el

\footnotetext{
${ }^{30}$ Relación del Tesorero Francisco Ortiz de Vergara al Presidente del Consejo de Indias, Don Juan Ovando, sobre los acontecimientos del Río de la Plata, en los años 1540 a 1573, Cabo Verde, 1573.

${ }^{31}$ Si bien Francisco Ortiz de Vergara y Ruy Díaz de Guzmán mencionan a Chaves entre los que participaron de la captura de Cabeza de Vaca, no acusan a Domingo Martínez de Irala. Aunque no hay evidencia que niegue su participación en el levantamiento, o que afirme su neutralidad -como sostuvo Sanabria en el panegírico de Chaves (1984) -, la participación en la entrada con Cabeza de Vaca debió impedirle tomar parte en los preparativos del complot.

${ }^{32}$ Relación de los casos en que el capitan Ñuflo de Chaves a servido a Su Magestad desde el año de quinientos y quarenta, Santa Cruz de la Sierra, 1561. El subrayado fue agregado para destacar que Chaves aporta a la expedición una cantidad menor de hombres que Irala, pero ocupando un lugar de paridad con el organizador.

${ }^{33}$ Información de servicios de Ñuflo de Chavez, Santa Cruz de la Sierra, 1561.
} 
alineamiento de los hombres venidos del Perú a ese efecto confirman su participación orgánica en el partido iralista.

Pertenecer al partido Iralista era compartir un proyecto común en relación con la conquista: la búsqueda del camino a la Tierra Rica. Resulta difícil pensar que la noticia de que la Sierra de Plata ya había sido conquistada por los españoles del arco peruano cambió las perspectivas de los hombres rioplatenses y propició un mayor interés por permanecer en el Paraguay, como sostiene Roulet (1993:227). Esa idea no permite explicar la nueva expedición organizada en 1553, conocida como la Mala Entrada, que no por fracasar dejó de ser un nuevo intento en el avance hacia la tierra de los metales. El mismo tenor tuvo la entrada organizada dos años después, que debió ser suspendida por la llegada de noticias desde España, con la provisión real del nombramiento de Irala como gobernador del Río de la Plata y la autorización para repartir indios en encomienda entre los pobladores de Asunción. Esta novedosa circunstancia ocasionó un giro en las aspiraciones de este viejo capitán, antaño interesado en llegar al Paititi, y ahora apaciblemente asentado -y amancebado- en Paraguay. Pero no significó un cambio de paradigma entre los hombres que lo habían acompañado. Chaves siguió embanderando la causa del descubrimiento del Candire, y desde hacía unos años el Río de la Plata contaba con un nuevo socio: Hernando de Salazar.

\section{Hernando de Salazar: socio, diplomático, mediador}

El capitán Hernando de Salazar arribó a América con la armada de Diego de Sanabria. Su información de servicios destaca que desde el momento en que llegó a Asunción, en 1552, fue leal al gobernador Irala. Lo demostró posicionándose a su favor en la discusión que por el año 1552 dividía opiniones acerca de la organización de una nueva entrada al Candire. También cuando a poco de salir de Asunción para la Mala Entrada recibieron noticias de un nuevo levantamiento de Diego de Abreu. En la expedición de 1553, por su parte, Salazar participó "a su costa y minsion [...] y ayudo a otras personas de su conpañia con caballos y hazienda, [...] en donde padeçio grandes trabajos y perdidas de caballos y azienda" (Julien, 2008: $121^{34}$ ). De esa manera, se fue configurando el perfil de este nuevo capitán que más tarde acompañó a Chaves a los Xarayes, expedición en la que colaboró con dos bergantines y varios caballos cuya pérdida lamentó en su información de servicios de 1561 (Julien, 2008: 122 $2^{35}$ ). No resulta extraño, entonces, que en el momento de resolver el conflicto entre Chaves y Manso fuera Salazar quien lo acompañara a la Ciudad de los Reyes. El lugar coprotagónico asumido por éste en la empresa de la conquista del oriente boliviano cristalizaría en el cargo del alguacil mayor de la gobernación de Mojos, en el que fue nombrado por el virrey Marqués de Cañete.

Además de la inversión en bienes materiales para la conquista, Salazar aportó sus aptitudes de diplomático y mediador. Se presentaba ante sus pares como un gran conciliador, aspecto que fue destacado por los testigos de su probanza de servicios.

\footnotetext{
${ }^{34}$ Información de Servicios de Hernando Salazar, Santa Cruz de la Sierra, 1562-1563.

${ }^{35}$ Información de Servicios de Hernando Salazar, Santa Cruz de la Sierra, 1562-1563.
} 
Por ejemplo, durante el viaje hacia América, en el que se produjo un motín contra el capitán de la nave, Salazar intervino para evitar que lo matasen. Juan Campos, presente en aquella ocasión, destacó sus capacidades persuasorias, presentándolo como un gran mediador en los momentos de tensión (Julien, 2008: 158 ${ }^{36}$ ). De la misma manera actuó cuando al llegar a Asunción encontró la ciudad dividida entre los que estaban a favor y quienes estaban en contra de que se realizara la nueva expedición por el río Paraguay. Todos los testigos interrogados coincidieron en que su intervención fue decisiva para la resolución del conflicto (Julien, 2008: 143, 147, 155 $5^{37}$ ). Su inclinación por la iniciativa de Irala lo inscribió en el bando de aquel y allanó el camino para la posterior alianza con Chaves. En virtud de ello, algunos años después tuvo lugar su intervención en el conflicto entre los de Asunción y Andrés Manso. Los testigos de su información de servicios reiteran con insistencia que si la captura de Manso pudo llevarse a cabo sin muertes ni escándalos fue por "la buena horden y consejo y pareçer que dio el dicho Hernando de Salazar", sin la cual "el dicho capitan Andres Manso no se prendiera, a lo menos costare mas de vna vida porque el dicho capitan Andres Manso estaba en arma con su gente" (Julien, 2008: 154 ${ }^{38}$ ).

Las capacidades interpersonales de este capitán no se limitaban a su intervención en la resolución de conflictos. La información sobre su actuación en Indias destaca su contribución con caballos y armas para la hueste asunceña, entregando incluso los propios a favor de los enfermos o heridos (Julien, 2008: 12739). En la Mala Entrada “ayudo a [... ] Domingo de Yrala [...] faboresçiendo algunos soldados que no tenian caballos ni armas, dandoles el de su propia azienda caballos”40. El mismo reconocimiento se reiteraría en la entrada a los Xarayes, cuando al enfrentarse con los chiquitos nuevamente proveyó de caballos y armas a quienes habían perdido los suyos en la batalla (Julien, 2008: 129, $145-146,153)^{41}$.

En Hernando de Salazar Chaves encontró un capitán leal al grupo que se identificaba con los intereses de Irala, un socio para organizar las expediciones y un mediador de fuste, un nexo negociador con otros españoles, ya fueran pares, funcionarios de gobierno o subordinados. Esto último le permitió, entre otras cosas, construir un fuerte vínculo de lealtad entre la hueste y ambos capitanes a prueba de momentos tensos y de conflictos como en el enfrentamiento entre Chaves y Manso, con el que cerramos este conjunto de elementos dinamizadores de la empresa conquistadora cruceña.

\footnotetext{
${ }^{36}$ Información de Servicios de Hernando Salazar, Santa Cruz de la Sierra, 1562-1563.

${ }^{37}$ Información de Servicios de Hernando Salazar, Santa Cruz de la Sierra, 1562-1563.

${ }^{38}$ Información de Servicios de Hernando Salazar, Santa Cruz de la Sierra, 1562-1563.

${ }^{39}$ Información de Servicios de Hernando Salazar, Santa Cruz de la Sierra, 1562-1563.

${ }^{40} \mathrm{Cf}$. Los testimonios de Juan Campos y Juan Vazquez Barrado en la Información de Servicios de Hernando Salazar, Santa Cruz de la Sierra, 1562-1563 en Julien, 2008: 127, 132, 141.

${ }^{41}$ Información de Servicios de Hernando Salazar, Santa Cruz de la Sierra, 1562-1563. Aunque el documento que atestigua a favor de Salazar fue redactado con el propósito de resaltar los servicios prestados al rey, debemos destacar que los testigos no sólo coinciden sino que además agregan información que no está presente en las preguntas que responden.
} 


\section{La hueste conquistadora de Santa Cruz de la Sierra. Recorridos previos y ambiciones comunes. 1540-1560}

De los 170 hombres que salieron de Asunción en 1558, sólo la mitad llegó a participar en la fundación de Nueva Asunción en 1559. Cuando estalló el conflicto con Andrés Manso, Chaves y Salazar viajaron a la Ciudad de los Reyes para entrevistarse con el virrey y la hueste que los acompañaba se quedó allí, en compañía de Manso. Al regreso de Chaves la rebelión de Manso no despertó adhesiones entre los asunceños, quienes esperaron el retorno de sus capitanes refugiados entre los chiriguanos de Vitupué $^{42}$ (Julien, 2008: $111^{43}$ ).

La lealtad de aquel grupo de hombres en torno a la causa chavista no radicaba en que compartieran un origen y trayectoria comunes. Diríamos lo contrario: para 1561 cada uno de ellos contaba con un recorrido singular en las tierras americanas. Una muestra de esto es el origen de los testigos presentados por Chaves y Salazar en las informaciones de servicios redactadas en 1561. En el caso de Salazar, cinco lo conocían desde que se embarcaron con él en España (Juan Campos, Hernán Campos, Juan Vazquez Barrado, Francisco Hernández y Domingo Osbaez) y tres estaban en Asunción cuando él llegó (Ñuflo de Chaves, Francisco Rengifo y Bartolomé de Moya). De los seis testigos de Chaves, tres viajaron a América con él (Diego de la Palma, Antonio Conejero y Juan de Pedraza), dos estaban en Asunción cuando él llegó, con lo cual habían formado parte ya de la armada de Pedro de Mendoza (Bartolomé de Moya y Anton Cabrera), y el último llegó con él desde Perú a fines de la década del '40 (Bernabe Sanchez). Antón Cabrera se desempeñaba como contador del rey al momento de dar su testimonio. Asumimos que hacerlo requería saber leer y escribir. No es el caso de Domingo Osbaez, de quien se dejó asentado que "tiene 62 años y no sabe escribir" (Julien, 2008: 15444), y de Bartolomé de Moya, Diego de la Palma y Bernabé Sánchez, quienes no firmaron la declaración porque no sabían escribir (Julien, 2008: 88, 86, 8345). Con hombres de procedencia diversa, que formaban parte de las armadas de Pedro de Mendoza, de Álvar Núñez Cabeza de Vaca, de Diego de Sanabria, por el arco rioplatense, y desde el Perú en 1549 y en 1560, durante los años previos a la fundación de Santa Cruz de la Sierra fue conformándose un grupo de hombres a quienes los aunó haber hecho propio un proyecto de conquista que albergaba la promesa de valer más, de lograr preeminencia y reconocimiento social cuando se alcanzara la tierra de los metales. Incluso cuando en Perú se agudizaron los conflictos por el botín de la conquista y se restringieron las oportunidades de ascenso social, el Río de la Plata ofreció esperanzas de alcanzar el propósito que los había lanzado a América. El recorrido de Bernabé Sánchez es un ejemplo. Su entrada a América había sido por Perú, y formó parte del grupo de 80 hombres que acompañaron Chaves de regreso a Asunción a fines de la década del ' 40 . En 1553 participó en la Mala Entrada y en 1558 en la expedición a los Xarayes (Julien,

\footnotetext{
${ }^{42}$ Sobre los chiriguanos de Vitupué ver nota 21.

${ }_{43}^{43}$ Documentos referentes a la fundación de Santa Cruz de la Sierra, Lima, 1561.

${ }^{44}$ Información de Servicios de Hernando Salazar, Santa Cruz de la Sierra, 1562-1563.

${ }^{45}$ Información de servicios de Ñuflo de Chavez, Santa Cruz de la Sierra, 1561.
} 
2008: 76-77 y 8246) que culminaría en la fundación de Santa Cruz de la Sierra, donde, según el documento del reparto de encomiendas de indios realizado en abril de 1561, le sería encomendada la parcialidad de "Parche, prençipal de Macariono" (en Julien, 2008: $104^{47}$ ).

El peso de la identidad que aunaba a los hombres de Chaves se hizo evidente en circunstancias en que otras personas, instituciones, proyectos y ambiciones pusieron obstáculos al avance de los conquistadores desde el Paraguay al piedemonte. Hasta aquí presentamos aquellos factores y circunstancias que a nuestro entender desempeñaron un papel dinamizador en la iniciativa de conquista conducida por Chaves. La alianza estratégica con Irala, su participación a favor del bando comunero de Asunción, las expediciones en las que tomó parte, la embajada ante las autoridades del Perú, la sociedad con una figura diplomática como Hernando de Salazar, la lealtad de la hueste emanada del proyecto que la mancomunaba con su capitán fueron las circunstancias que le permitieron a Chaves acumular insumos para abrirse camino desde Asunción hasta los confines orientales de Charcas. El motor de la conquista, sin embargo, precisa ser matizado con los obstáculos que en algunos momentos detuvieron y en otros ralentizaron su marcha.

\section{Proyectos contrapuestos, disputas políticas y territoriales}

Si lo que distinguía al bando iralista en el Río de la Plata era su iniciativa para salir en busca de información y caminos para llegar a la tierra del Candire, la política de los oficiales del Río de la Plata -y especialmente la del factor Pedro de Orantes- se caracterizó por oponerse a la organización de entradas con ese fin. En 1555 Irala le envió una carta al rey en la que denunciaba a los oficiales reales por haberse opuesto a que realizara una entrada a los Xarayes en el año 1545, a causa de cuya pertinaz negativa se vio obligado a renunciar. Aquel descargo de Irala también incluía acusaciones a los oficiales reales de conspirar contra él cuando esperaban que Chaves regresara de Perú en la expedición de 1547, destituyéndolo de su cargo y nombrando a Gonzalo de Mendoza como gobernador (Irala 1962 [1555]: 277). Pedro de Orantes argüía que una nueva expedición dejaría desprotegida la ciudad por la gran cantidad de hombres que se ausentarían y temía que en esas circunstancias se precipitara un ataque indígena. Es que según él, el empleo de tantos indios amigos en una expedición provocaba una mayor exigencia sobre los que se quedaban. Por esas razones propuso que Irala se quedase hasta que llegaran los refuerzos de hombres que le habían solicitado a la corona (Levillier, 1915: 115, 118, 12048). No obstante, la carta de Irala tuvo el resultado esperado. En 1557 una Real Cédula ordenaba a los oficiales reales del Río de la Plata que se limiten a sus funciones de resguardar la real hacienda y que no se entrometan en los asuntos del gobierno ${ }^{49}$. Sin embargo, Orantes reiteró su posición en contra de nuevas entradas por el

\footnotetext{
${ }^{46}$ Información de servicios de Ñuflo de Chavez, Santa Cruz de la Sierra, 1561.

${ }^{47}$ Documentos referentes a la fundación de Santa Cruz de la Sierra, Lima, 1561.

${ }^{48}$ Probanza de méritos y servicios del Factor y oficial Real pedro Dorantes. Copias de cartas al Rey y otros escritos, Asunción, 1581.

${ }^{49}$ GGV 86/1362, Real Cédula a los oficiales de las provincias del Río de la Plata, Valladolid 1557.
} 
río Paraguay cuando Chaves organizó la expedición a los Xarayes en 1558, arguyendo actuar a favor de la protección de los guaraníes a cargo de la corona. Esta vez sus razones señalaban la existencia de una divergencia mayor en torno a las prioridades de la gobernación del Río de la Plata, ya que Orantes sostenía no estar de acuerdo con la entrada porque consideraba que poblar el puerto de San Francisco para comunicar la gobernación con el mar era mucho más urgente y útil que poblar los Xarayes (Levillier, 1915: $\left.226^{50}\right)$.

Si bien la reiterada oposición de Pedro de Orantes a la organización de nuevas entradas fue soslayada, no dejó de presentarse como un factor de disputa por las políticas de asignación de recursos de la gobernación y, sobre todo, por las razones para poblar Asunción, permanecer en ella o partir. Es importante destacar la condición de oficial real de Pedro de Orantes, porque el resguardo de los intereses de la Corona otorgaba un plus de legitimación a su discurso frente al de otros españoles presentes en esas disputas. No obstante, si el lugar de autoridad desde el cual argumentó no fue suficiente para evitar que se realicen las expediciones que cuestionaba fue porque la distancia y el aislamiento diluyeron su poder. Esas circunstancias habilitaron una mayor incidencia de criterios individuales o facciosos a la hora tomar decisiones, quedando en la práctica en igualdad de condiciones con los conquistadores.

Las disputas surgidas en torno al lugar que ocupaba la conquista del Paraguay en los proyectos de los asunceños no se limitaron a los enfrentamientos entre Pedro de Orantes con Irala y Chaves. Otros hombres, como Pedro de Segura y Francisco Ortiz de Vergara, recogieron el legado de Cabeza de Vaca y desafiaron las iniciativas de Chaves.

\section{Xarayes divide aguas. Un bando anti-chavista en Asunción. 1556-1566}

Entre los hombres que acompañaron a Chaves al regresar de su primer viaje a la capital virreinal del Perú estaba el capitán Pedro de Segura, quien, según la versión de Ruy Díaz de Guzmán, desde el inicio de su estadía en Asunción intentó mantener cierta autonomía respecto del bando iralista. Pero ante el rebrote del enfrentamiento entre leales y comuneros en 1550-1551, y para contribuir al restablecimiento de la paz en la gobernación, Pedro de Segura, Francisco Ortiz de Vergara, Alonso Riquelme de Guzmán y Gonzalo de Mendoza acordaron la paz con Irala contrayendo matrimonio con sus hijas (Díaz de Guzmán [1612] 1910: 67). A partir de entonces, Segura siguió las órdenes de Irala, saliendo a sofocar levantamientos de guaraníes o buscando provisiones reales al Río de la Plata. Sin embargo, la alianza matrimonial no trascendió la vida de su mentor y al morir Irala afloraron los conflictos con sus sucesores, ahora liderados por Ñuflo de Chaves. El primero tuvo lugar en la expedición a los Xarayes. Cuando se desviaron hacia el oeste del territorio que debían poblar por mandato de la gobernación del Río de la Plata, y luego del revés sufrido frente a los chiquitos en el cual hubo pérdidas de hombres y caballos, Gonzalo de Casco, Rodrigo de Suna y Pedro de Segura se amotinaron junto con setenta hombres, "lleuaron consigo mill y quinientos yndios

\footnotetext{
${ }^{50}$ Probanza de méritos y servicios del Factor y oficial Real Pedro Dorantes. Copias de cartas al Rey y otros escritos, Asunción, 1581.
} 
amigos, y lleuando clerigos y todos ofiçiales que para la dicha poblaçion traia, y en punto de guerra, dia de San Juan en la mañana, se fueron; y se boluieron a la çiudad de la Asunçion" (Julien, 2008: 5551). La división de la hueste fue uno de los acontecimientos más adversos para Chaves y sus hombres en aquella expedición, porque mermó las tropas a la mitad luego de más de un año de haber salido de Asunción, con pocas provisiones, en un ambiente hostil y siendo blanco de constantes ataques por parte de los chiquitos.

Sin embargo, la versión relatada desde Asunción sobre el cisma era sensiblemente distinta. A los ojos de quienes quedaron en Asunción, lo que fue calificado por Chaves y Salazar como motín en contra del servicio de su majestad, fue una reacción frente al incumplimiento de Chaves del mandato de poblar los Xarayes ${ }^{52}$. Por eso, al regresar Chaves a Paraguay en 1564, la tensión con Francisco Ortiz de Vergara -que era el gobernador del Río de la Plata desde la muerte de Domingo Martínez de Irala- se hizo evidente. Ortiz de Vergara había llegado a Asunción en 1542, en la misma armada que Nuflo de Chaves, pero a diferencia de éste se había alineado en el bando leal a Cabeza de Vaca. A pesar de haber sido apresado por los comuneros durante el golpe contra Cabeza de Vaca, persistió en su apoyo a Juan de Salazar Espinosa, a quien el gobernador depuesto había dejado un poder para gobernar; lo apoyó incluso luego de que Salazar de Espinosa fuera apresado por los oficiales reales. Acompañó a Diego de Abreu en 1549 en su levantamiento contra Francisco de Mendoza, a la sazón teniente de gobernador de Irala, y fue su emisario a España, aunque el viaje se malogró por el naufragio de su nave. De regreso a Asunción se casó con una hija de Irala. En 1555 Irala le otorgó a Ortiz de Vergara el cargo de capitán y justicia mayor de la población y descubrimiento de los Xarayes, pero al morir aquél en 1556 asumió la gobernación del Río de la Plata, por lo que delegó en Chaves la misión de poblar los Xarayes. Chaves no sólo incumplió el mandato sino que pobló otras tierras que puso bajo la supervisión directa del gobierno virreinal del Perú.

Por eso, cuando Chaves llegó a Asunción en 1564 y el gobierno acordó proveerlo de bienes para que se llevara su casa y su familia a Santa Cruz, autorizando la salida de un grupo de asunceños para acompañarlo y poblar la ciudad que acababa de fundar, y "syn pedirle quenta de su jornada e de no haver fecho la poblaçion de los xarayes e de otras muchas cosas de que se le pudiera pedir", Ortiz de Vergara no olvidaba que la fundación de Santa Cruz de la Sierra había sido realizada "a costa desta çibdad y en tierra y parte descubierta y conquistada por los vezinos e moradores desta çiudad tan a su costa e misyon y que con justo y derecho titulo les perteneçe" ${ }^{53}$. Por eso decidió salir de Asunción con Chaves para ir ante las autoridades virreinales solicitando auxilio, puesto que los hijos de la ciudad "son yngratos ayudandola siempre a menoscabar y

\footnotetext{
${ }^{51}$ La relación general de todo los susodicho que tomo en publica forma Bartolome Gonzalez escribano de Cabildo, tesorero de la Asunción, Lima, 1560.

52 GGV 90/ 1440: 5-6, Carta del Cabildo de la Asunción del Paraguay, fecha 2 de octubre 1564, sobre los sucesos ocurridos en el Río de la Plata, Asunción, 1564.

${ }^{53}$ GGV 90/1440: 9, Carta del Cabildo de la Asunción del Paraguay, fecha 2 de octubre 1564, sobre los sucesos ocurridos en el Río de la Plata, Asunción, 1564.
} 
gastar su poca posibilidad y no a sustentar ni favoreçer en cosa alguna"54, en clara referencia a Chaves.

Al llegar a Santa Cruz de la Sierra Chaves decidió retener a Ortiz de Vergara y al obispo de La Torre ${ }^{55}$ y salir a Charcas con Pedro de Orantes, factor del rey en el Río de la Plata, para resolver la disputa a su favor. Hernando de Salazar, a cargo del gobierno de Santa Cruz por la ausencia de Chaves, sostuvo no haber podido retenerlos por mucho tiempo porque había mucha gente en la ciudad y eso ocasionaba conflictos. Las declaraciones de Ortiz de Vergara ante la Audiencia de Charcas incluyeron graves acusaciones contra Chaves. Ello no impidió que Ortiz de Vergara fuera desplazado del cargo de gobernador y reemplazado por Juan Ortiz de Zárate. Aunque finalmente resuelta a su favor, esta circunstancia inicialmente adversa a los intereses de Chaves supuso tres niveles de disputa política: 1) el rebrote del enfrentamiento entre las dos facciones del Río de la Plata - la iralista y la alvarista, o la leal y la comunera-, que encarnaban dos concepciones distintas respecto de las formas y objetivos de la conquista; 2) los límites del poder de las instituciones gobernantes para contener la iniciativa privada en un contexto en el que la búsqueda de recompensa por las inversiones desembolsadas por los conquistadores era prioritaria frente a las políticas de poblamiento, colonización y abastecimiento emanadas desde las instituciones del estado colonial, máxime en el caso de la gobernación del Río de la Plata, área marginal y frecuentemente aislada en la que el poder de la corona se volvía débil frente al ejercicio local del poder; 3) la ausencia de claridad sobre los alcances y límites de la gobernación del Río de la Plata que, aunque formalmente era una parte del Virreinato del Perú, había funcionado con altos niveles de autonomía respecto de éste, recurriendo con frecuencia a la comunicación directa con la Corona por medio de sus oficiales reales. En estas circunstancias, no tardó en emerger la disputa en torno a cuál de ambas autoridades tendría injerencia directa sobre las nuevas tierras conquistadas. El conflicto entre Ñuflo de Chaves y Andrés Manso es el paradigma de este último punto.

\section{Andrés Manso versus Nuflo de Chaves. 1559-1564}

Una de las particularidades más interesantes de la gobernación de Mojos fue que debe su origen a una iniciativa rioplatense y a la vez su existencia formal al aval institucional peruano. Sin embargo, es difícil imaginar que desde la preparación de la expedición a Xarayes estuviera en los planes de Chaves conseguir el título de teniente de gobernador de Mojos, que le fue otorgado en 1560. Por el contrario, el inesperado

\footnotetext{
${ }^{54}$ GGV 90/1440: 10, Carta del Cabildo de la Asunción del Paraguay, fecha 2 de octubre 1564, sobre los sucesos ocurridos en el Río de la Plata, Asunción, 1564.

${ }^{55}$ La versión de Ortiz de Vergara señala que al llegar a Santa Cruz de la Sierra fue apresado por Chaves (GGV 91/1483: 9, Carta del Cabildo de la Asunción del Paraguay, fecha 2 de octubre 1564, sobre los sucesos ocurridos en el Río de la Plata, Asunción, 1564.). Sin embargo, la Audiencia de Charcas no admitió que se interrogue sobre esa pregunta a los testigos presentados por él. Aunque podemos suponer que la información aportada por Ortiz de Vergara haya sido difamatoria de Chaves, las referencias de los testigos de la información de Hernando de Salazar a las disensiones que había en Santa Cruz estando allí el gobernador y el obispo permiten suponer que la prisión de Ortiz de Vergara fue real (Julien, 2008: 170-211).
} 
encuentro con Andrés Manso determinó ampliamente el destino del área cruceña a partir de 1559. El imprevisto que se interpuso en el camino de Chaves a la tierra del Candire retrasó sus planes primero y luego los integró definitivamente a una dinámica colonial peruana que limitó su autonomía y la potencialidad de sus aspiraciones.

Con la hueste mermada por la división de Pedro de Segura, los asunceños llegaron a la tierra de los tomaguacíes, el mismo lugar al que Chaves había llegado con Irala una década atrás y desde donde había partido al Perú. E1 1 de agosto de 1559 fundaron Nuestra Señora de la Nueva Asunción, donde se aprovisionarían para seguir el camino al noroeste. Enviado por Chaves a buscar guaraníes amigos que los acompañaran en la nueva etapa de la expedición, Diego de Mendoza se topó con Andrés Manso, quien llegaba a poblar aquella tierra por mandato del virrey Andrés Hurtado de Mendoza, Marqués de Cañete, para contener los ataques de los chiriguanos que asediaban con frecuencia a los indios encomendados en los valles aledaños (Levillier, 1921: 348 ${ }^{56}$ ).

Ante la dificultad de resolver a quién correspondía el derecho de poblar ese territorio, acordaron que Chaves viajase a la Ciudad de los Reyes, mientras Manso esperaba con los hombres de ambas huestes que volviera con la provisión que dictara el virrey. Desconocemos las razones por las cuales Manso se quedó en Nueva Asunción, y los documentos disponibles no sugieren nada al respecto. Pudo haber considerado que quedarse ahí era garantía de no perder el derecho sobre la tierra frente a su contrincante. Probablemente haya confiado en que el mandato virreinal que lo había destinado a poblarla le aseguraba el derecho sobre aquella conquista. Por su parte, Chaves tenía razones de peso y de sobra para querer ir frente al virrey, ya que no contaba con una autorización del gobierno del Río de la Plata para poblar aquellas tierras; de hecho, había llegado hasta ahí transgrediendo el mandato de asentarse en los Xarayes, y yendo a la Ciudad de Los Reyes tendría la posibilidad de conseguir el respaldo del gobierno virreinal. Chaves supo advertir la importancia de intervenir personalmente en la negociación con el poder virreinal para poder resolver el conflicto a su favor; el antecedente como embajador ante La Gasca en 1549 debió favorecerlo. Pero la definición del Marqués de Cañete -Andrés Hurtado de Mendoza, virrey del Perú en 1559- a favor de Chaves no puso fin al conflicto con Manso. En el camino de regreso a Nueva Asunción recibió noticias de la resistencia de éste a acatar las provisiones del virrey: Manso se había levantado y amenazaba a sus hombres, quienes se refugiaron entre los chiriguanos hasta que Chaves y Salazar volvieran (Julien, 2008: 110-111 57 ).

Luego de algunos días de demostraciones de fuerza mutuas, el 25 de julio de 1560 Manso fue capturado y llevado ante los tribunales de La Plata (Julien, 2008: 109$118^{58}$ y $157^{59}$ ). Unos meses después, desde Santa Cruz, solicitaron al virrey que Manso se presente ante las autoridades para dar explicaciones por el maltrato del que eran víctimas los indígenas de los llanos y por los disturbios y levantamientos que provocaba

\footnotetext{
${ }^{56}$ Carta del Marqués de Cañete a S.M., Lima, 1560.

${ }^{57}$ Documentos referentes a la fundación de Santa Cruz de la Sierra, Lima, 1561.

58 Documentos referentes a la fundación de Santa Cruz de la Sierra, Lima, 1561.

${ }^{59}$ Información de Servicios de Hernando Salazar, Santa Cruz de la Sierra, 1562-1563.
} 
entre ellos. Al parecer Manso se había escapado de la prisión y había huido a los llanos donde, aliado con los chiriguanos del Parapetí, atacaba a los pobladores chané de la región. En el mismo documento (una relación de lo servido por Ñuflo de Chaves al rey desde 1557) se advertía que "algunas personas de la dicha probinçia de las Charcas an entrado y entran en donde esta el dicho Andres Manso, y se juntan con el, y lo faboresçen con calor y ayuda que tienen de los vecinos, y se a disimulado y disimula el castigo desto", por lo que solicitaban sanciones para los involucrados en esos disturbios y la prohibición de la entrada a los llanos (Julien, 2008: 112-113 ${ }^{60}$ ). No se trataba sólo de una reminiscencia de la rivalidad entre Chaves y Manso. La situación acusada por los cruceños también fue advertida desde los centros de poder colonial. En octubre de 1561 el presidente y los oidores de la Audiencia de Charcas enviaron una carta al rey con noticias sobre el territorio bajo su jurisdicción, en cuya ciudad sede encontraron "ciertos vandos entre los vezinos y moradores desta çiudad que unos an faborecido la boz del capitan Manso nuevo poblador de una tierra questa cerca desta çiudad de Indias que se dizen Chiriguanaes - y otros la del capitan Nuflo de Chaves que tiene la poblacion y descubrimyento de los mojos los quales se an querido mal" (Levillier, 1922: $23^{61}$ ). La rivalidad entre Chaves y Manso generaba adeptos y detractores de ambos bandos en La Plata. Sin duda, el desempeño de ambos capitanes en las tierras del este del piedemonte repercutía entre los vecinos de Charcas. Por su parte, la Audiencia de Charcas y el virrey temían que el conflicto en torno del cual se alineaban los vecinos de La Plata terminara en una guerra civil. A los efectos de evitar un enfrentamiento mayor, el virrey Conde de Nieva envió a Juan de Medina Avellaneda a la gobernación de Mojos para mediar entre ambos capitanes (Maurtúa, 1906: 34-3762 y 57-7163). La evaluación del resultado fue dispar, porque mientras el virrey y su enviado destacaron la importante tarea de pacificación realizada, la Audiencia de Charcas sostuvo que el intento no rindió sus frutos porque las partes en conflicto desconfiaban de la imparcialidad del enviado (Levillier, 1922: $23^{64}$ ). Finalmente el regente de la Audiencia de Charcas se reunió con ambos y llegaron a un acuerdo de paz que incluía la entrega de mil quinientos pesos a Manso y de mil pesos a Chaves ${ }^{65}$.

A pesar de contar con una multiplicidad de voces acerca del conflicto, ninguna de las versiones es completa y, dadas la magnitud del enfrentamiento y sus repercusiones

\footnotetext{
${ }^{60}$ Documentos referentes a la fundación de Santa Cruz de la Sierra, Lima, 1561.

${ }^{61}$ Carta a SM del presidente y oidores de la audiencia de los Charcas, La Plata, 1561.

${ }^{62}$ Carta del virrey Conde de Nieva a S.M, dándole cuenta de las diferencias entre los capitanes Andrés Manso y Nuflo de Chávez, Lima, 1562.

${ }^{63}$ Información de méritos y servicios de Juan de Medina Avellaneda, Lima, 1572.

${ }^{64}$ Carta a SM del presidente y oidores de la audiencia de los Charcas, La Plata, 1561. La evaluación del presidente y los oidores de la Audiencia de Charcas sobre la mediación de Juan de Medina Avellaneda es parte de una carta enviada al rey que reportaba el estado de aquella tierra al momento de creación de la Audiencia. Sus integrantes destacaban la importancia de la nueva institución, señalaban su incumbencia en la resolución del conflicto entre Manso y Chaves y relativizaban la efectividad de las medidas tomadas desde Ciudad de Los Reyes, sede virreinal. Para destrabar la situación el presidente y los oidores de la Audiencia de Charcas propusieron dejar en sus manos la resolución del conflicto, argumentando que la mayor cercanía a las regiones en disputa habilitaría mejores condiciones de diálogo.

${ }^{65}$ GGV 89/1388.5, Diez cartas de la Audiencia de Charcas al Rey, La Plata, 1561-1567.
} 
entre los vecinos de Charcas, nos resulta tentador inferir a partir de las divergencias, de los silencios y de evidencia de otro orden las implicancias de un enfrentamiento que sólo en apariencia involucraba la competencia por la gloria de haber extendido los dominios coloniales del Perú más allá de la cordillera.

Desde Santa Cruz de la Sierra se expusieron acusaciones a las acciones de Manso entre los indígenas de los llanos del Parapetí. No menores son las que sostuvieron frente a la omisión de las autoridades judiciales de La Plata, que disimulaban el castigo de la colaboración de los vecinos de Charcas con Manso. La Audiencia de Charcas terminó mediando en el conflicto luego de hacer una evaluación negativa de la conciliación de Medina Avellaneda. Llegados a este punto, cabe preguntarse sobre la existencia de algún interés común entre Manso y la Audiencia de Charcas que explique la connivencia que denunciaban los vecinos de Santa Cruz de la Sierra. Por un lado, podemos afirmar que la política de Manso en los llanos estaba lejos de cumplir con el mandato de poblar para pacificar a los chiriguanos: Matarapa, embajador de los caciques chiriguanos de la región de Vitupué en 1561 declaró en Santa Cruz que "el capitan Manso los hizo juntar para yr a la guerra contra los yndios de los llanos [...] e lleuo consigo a Caype [Çaype] y Condurillo y otros caçiques" (Julien, 2008: 116 ${ }^{66}$ ). Manso también había convocado a los de Vitupué pero, temerosos de una advertencia de Chaves, se habían negado a participar de las rancherías contra los chané. Entonces tenemos a Manso aliado con los chiriguanos para hacer la guerra a los indígenas de los llanos, y a la Audiencia de Charcas cubriendo el costo legal de las acciones de Manso. ¿Cómo explicar este entramado político-militar? Una de las peticiones del cabildo de Santa Cruz al virrey y presidente y oidores de la Audiencia de Los Reyes aporta información al respecto:

"se a de pedir y suplicar a Su Exçelençia con toda ynstançia, como cosa que tanto ynporta a la paçificaçion, substentaçion y acreçimiento desta tierra, vezinos y pobladores della, que haga merçed a esta dicha çibdad que puedan sacar yndios de los pueblos que estan encomendados o se encomendaren para que siruan en las minas de Potosy, atento la sterelidad desta tierra, como esta dicho, y a que los naturales, mediante esto, se harran politicos y bendran mas presto en conosçimiento de las cosas de nuestra sancta fee catholica, pues de otras partes de los rreynos del Peru ban a seruir a las dichas minas, tanto y mas dystançia que ay desde esta provinçia a las dichas minas, espeçial que se tiene por espirençia verdadera que ay cantidad de yndios naturales desta tierra en las dichas minas y en la comarca de las Charcas en labranças y estançias de ganados, y biben sanos y contentos sin querer bolber a su naturaleza avnque an podido [...] y haziendose la dicha merçed, se cometa al gouernador o su theniente general que oy es para

\footnotetext{
${ }^{66}$ Documentos referentes a la fundación de Santa Cruz de la Sierra, Lima, 1561.
} 
que en el sacar de los yndios sea conforme a su cantidad sin que rresçiben bexaçion alguna" (Julien, 2008: $97^{67}$. Énfasis agregado).

El pedido de autorización del cabildo de Santa Cruz de la Sierra para que los nativos de los llanos cumplan sus servicios de encomienda en las minas de Potosí se inspira en el antecedente de Charcas, en cuya jurisdicción se encontraban indios de las tierras bajas trabajando tanto en la extracción de metales como en las haciendas de producción de bienes para el mercado interno de Potosí y alrededores. ¿Cuándo pudo haber comenzado dicha práctica? El apoyo de algunos vecinos de Charcas y el afán de la Audiencia por intervenir en la resolución del conflicto puede ser leído a partir de esta última evidencia. El estudio del tráfico de indios de las tierras bajas para satisfacer la demanda de mano de obra en minas y haciendas de Charcas fue abordado por varios autores, entre cuyos trabajos se señaló el rol de mediadores de los chiriguanos (Susnik, 1968; García Recio, 1988; Saignes, 1985, 1991; Combés, 2005, 2010; Coello Da Rosa, 2007). Lo que nos interesa destacar, es la incidencia de este factor económico en las relaciones políticas entre los conquistadores del oriente boliviano, y de éstos con las instituciones de gobierno colonial. La connivencia de algunos vecinos de La Plata con Manso y la oposición a Chaves probablemente tenga correlato con la oposición inicial de éste último a la participación de los chiriguanos de Vitupué en las rancherías de captura de indígenas chané (Julien, 2008: 116 ${ }^{68}$ ). Pero, por otra parte, entre los propios habitantes de Santa Cruz existía conciencia de la importancia de emplear a sus indígenas encomendados en las minas de Potosí, en la medida en que eso garantizaba el acceso a la plata, que de otra manera resultaba una quimera tan lejana como la tierra del Candire. El área cruceña, aunque en los márgenes de los dominios del Perú, terminaría integrándose al sistema de la economía colonial organizado en torno a la extracción de plata en Potosí (Assadourian, 1982; García Recio, 1988). En la inserción en el mercado interno surgido a partir de la actividad minera, Santa Cruz de la Sierra desempeñaría el papel de proveedor de mano de obra, para entonces escasa por los efectos de baja demográfica provocada por la conquista española en la sierra.

La oposición inicial de Chaves a la caza de indígenas de los llanos y al tráfico de nativos en el mercado potosino no demoraría en revertirse. Probablemente haya incidido la muerte de Manso en 1564, en quien tal vez se había confiado inicialmente esa tarea. En 1566 la Audiencia de Charcas designaba a Chaves como pacificador de los chiriguanos, y le asignaba la gente necesaria para castigarlos, así como también para poblar la tierra que Manso no había podido dominar ${ }^{69}$. Algunos años después Francisco Ortiz de Vergara, de regreso en España, relataba ante el presidente del Consejo de Indias, Don Juan Ovando, lo que era público en Santa Cruz de la Sierra: "para sacar misima [sic] gente de aquellas provincias al peru a potosi y a la plata para venderlos con una venta la menos disemulada que en mi vida e visto y esto uzase tan en general que lo hazen muchos y muy publicamente y el nufio que es el que govierna en su vivienda

\footnotetext{
${ }^{67}$ Documentos referentes a la fundación de Santa Cruz de la Sierra, Lima, 1561.

${ }^{68}$ Documentos referentes a la fundación de Santa Cruz de la Sierra, Lima, 1561.

${ }^{69}$ GGV 90/1388.8, Diez cartas de la Audiencia de Charcas al Rey, La Plata, 1561-1567.
} 
sacar pieças para este efeto y dar lugar a que otros las saquen con su licencia" (Levillier, 1915: $248^{70}$ ). A la información sobre el tráfico de nativos de la región cruceña a Potosí y del consentimiento de Chaves, añadía pues datos sobre la complicidad entre Chaves y los oidores de la Audiencia de Charcas para ese negocio, como el caso de:

"una doña luysa biuda mujer que fue de gomez de solis vecino de los charcas que el nufio de chaves les avia dado y embiado yndios y yndias con que hazia un yngenio de açucar esta vecina se dize publicamente que es muger del oidor Ricalde y esto se porque me lo dixeron muchas veces don bernaldino de meneses y doña maria de los Robles su muger y que lo tenian encubierto por ella gozar de los yndios y el de la plaza" (Levillier, 1915: $249^{71}$ ).

Aunque no podemos omitir que las declaraciones de Ortiz de Vergara estaban teñidas de la rivalidad que mantuvo con Chaves en el Río de la Plata, resulta verosímil pensar que tarde o temprano el destino de la gobernación de Mojos quedaría subordinado a las necesidades del epicentro de la economía colonial que era Potosí, y que debió contar con la participación de Chaves, su máxima autoridad de hecho. Esa subsunción de Santa Cruz de la Sierra al virreinato del Perú, y a Charcas en particular, nos motiva a postular que la oscilación de ambas instituciones coloniales en relación con la gobernación de Mojos - a veces contraria y otras favorable a Chaves y los asunceños- se debió a la inclusión de aquel territorio en un contexto mayor, que trascendía los intereses y la capacidad de accionar y de tomar decisiones por parte de los cruceños. Del análisis de esas situaciones se trata este tercer y último eje que proponemos para dar cuenta de la relación entre Ñuflo de Chaves y los demás españoles.

\section{La lógica de las oscilaciones: la intervención de las autoridades virreinales}

La provisión del Marqués de Cañete de 1561 a favor de Chaves y Salazar, que rectificaba los planes de poblamiento de la tierra de los chiriguanos encomendados a Andrés Manso, puede parecer una muestra de confianza del gobierno virreinal de Perú para con los asunceños. Otras situaciones previas y posteriores nos muestran la adopción de una política en apariencia errática del gobierno virreinal en relación con aquellos hombres del arco rioplatense, detrás de la cual nos animamos a afirmar la presencia de una estrategia de expansión peruana que en 1560 recién comenzaba a hacerse efectiva.

El primer antecedente tuvo lugar en 1549, cuando Chaves viajó a Ciudad de los Reyes como embajador del Río de la Plata. La Gasca vio entonces la oportunidad de descargar la tierra para evitar el rebrote de conflictos entre facciones de conquistadores, y en esa medida respondió a los pedidos de ayuda para la gobernación asunceña. El mismo sentido tuvo el nombramiento de Diego Centeno como gobernador de Paraguay, territorio que consideraba un espacio independiente del Río de la Plata, que serviría de

\footnotetext{
${ }^{70}$ Relación del Tesorero Francisco Ortiz de Vergara al Presidente del Consejo de Indias, Don Juan Ovando, sobre los acontecimientos del Río de la Plata, en los años 1540 a 1573, Cabo Verde, 1573.

${ }^{71}$ Relación del Tesorero Francisco Ortiz de Vergara al Presidente del Consejo de Indias, Don Juan Ovando, sobre los acontecimientos del Río de la Plata, en los años 1540 a 1573, Cabo verde, 1573.
} 
destino al excedente de hombres ávidos por salir a conquistar nuevos territorios. Que esa gobernación quedara a cargo de un hombre del Perú daba cuenta de la intención de reservar para el núcleo peruano los territorios que se extendían al este de los andes (Levillier, 1921: 136-16172). Además, para La Gasca, conocido como el pacificador del Perú, la concesión a Centeno de la gobernación del Paraguay constituía una forma de gratificación y recompensa por la participación de éste en el bando realista ${ }^{73}$.

Cuando, veinte años después, el virrey Marqués de Cañete nombró a su hijo gobernador de Mojos, operaría la misma lógica que aseguraba que la nueva población de las tierras bajas quedara bajo la supervisión directa del Virreinato del Perú. Se trataba de minimizar la autonomía de los de Asunción y de volverlos útiles para las necesidades del gobierno virreinal. Por otra parte, la llegada del contingente de conquistadores asunceños asentados en Nueva Asunción tuvo lugar en un momento en el que los ataques de los chiriguanos sobre las haciendas de los vecinos de Charcas representaban un grave problema. Por eso habían enviado a Manso, y por eso la nueva ciudad fundada por Chaves, así como la nueva gobernación que le autorizaban a erigir, resultaban de gran ayuda. Sin embargo, la evaluación que el virrey y los vecinos de Charcas hicieron de esa situación no fue la misma. Mientras que el virrey suponía que el regreso de Chaves a Nueva Asunción con un grupo de españoles de Ciudad de Los Reyes garantizaba el poblamiento de la región cruceña y con ello el control de los chiriguanos, para los vecinos de Charcas implicaba un peligro. La cercanía de Nueva Asunción y Santa Cruz a Potosí -en comparación con la Asunción de veinte años atrás-, así como la esterilidad de aquellas tierras en materia de metales preciosos, los hacía correr el riesgo de que "estos de Nuflo de Chaves en no allando tierra que les contente an de volver a esta tierra a avrasarla"74.

No fue la única vez que los españoles de Perú manifestaron sus temores por los efectos perjudiciales que podía tener la llegada de hombres provenientes de regiones lejanas y pobres. A fines de 1563 corrían fuertes rumores sobre la inminente visita al Perú de la comitiva de Ortiz de Vergara, gobernador del Río de la Plata. Entonces el virrey Conde de Nieva solicitó al rey que no consintiera que los asunceños fueran al Perú "porque aquella tierra no tiene riqueza de metales y la gente de ella procura de buscarlos y no tiene otra salida para ello sino es venir al peru como lo ha hecho otra vez y lo haze agora y lo hara todas las vezes que ubiere numero crecido de gente en aquella governacion y sino se remediase como digo podria ser causa de algun ynconviniente" (Levillier, 1921: 535 ${ }^{75}$ ). Que las tierras pobres en metales terminaban expulsando a los hombres al Perú ya no era una novedad, según se desprende del pedido del virrey. Por su parte, la Audiencia de Charcas, ante la noticia de la visita de Ortiz de Vergara y

\footnotetext{
${ }_{72}$ Carta del Licenciado La Gasca al Consejo de Indias, Lima, enero de 1549.

${ }^{73}$ Según Ana María Presta (1997: 66), la participación de Diego Centeno en contra del bando pizarrista implicó la ejecución de Francisco de Almendras, quien considerara a aquél como su hijo afecto; cabe entonces dimensionar, a partir de este dato, la recompensa de La Gasca al nombrarlo gobernador del Paraguay -aunque Centeno nunca ejerciera el cargo.

${ }^{74}$ GGV 90/1388.3, Diez cartas de la Audiencia de Charcas al Rey, La Plata, 1561-1567.

${ }^{75}$ Carta del virrey Conde de Nieva a S.M, sobre las noticias que tenia del Rio de la Plata, Lima, 1563
} 
sus hombres, de quienes se creía que no volverían al lugar de origen, buscó que fueran entretenidos para que demoraran su llegada a Charcas ${ }^{76}$. En estas circunstancias Chaves, que desde hacía años mantenía un pleito con la facción que representaba el gobernador Ortiz de Vergara, se convirtió en un aliado de la Audiencia de Charcas y viceversa. El trato incluyó que aquél retuviera a esos hombres en Santa Cruz de la Sierra a cambio de la destitución del gobernador del Río de la Plata, así como su reemplazo por un hombre del Perú: Juan Ortiz de Zárate ${ }^{77}$.

Por un lado, comprobamos que se sostuvo la negativa de los distintos virreyes del Perú de proveer un gobernador al Río de la Plata que no fuera vecino del Perú. Ello garantizaría un control directo sobre aquellas regiones. Sin embargo, ni Diego Centeno ni García Hurtado de Mendoza llegaron a ejercer las gobernaciones del Paraguay y de Mojos respectivamente. Habría que esperar al nombramiento de Juan Ortiz de Zárate para que la política de expansión desde Perú fuera concretada en los hechos. Por otra parte, las tierras ubicadas al este del piedemonte andino cumplieron funciones que les fueron asignadas a partir de las necesidades que imponía la coyuntura peruana. Así, a fines de la década del '40 el temor a un rebrote de las guerras civiles impuso liberar la tierra de los hombres de Asunción. Cuando los ataques indígenas arreciaron sobre las haciendas de la frontera chiriguana, la necesidad de ocupar los llanos justificó el apoyo virreinal a los advenedizos asunceños, mientras se desplegaba un conflicto entre Chaves y Manso de raíces más profundas que la mera disputa por la conquista de un territorio. La demanda de mano de obra para el mercado potosino y sus alrededores terminó de ceñir el sueño de los asunceños de llegar a la Sierra de la Plata y los volvió pobladores de un enclave de provisión de mano de obra indígena, asentado en la periferia del territorio colonial, pero integrado de manera plena a su economía.

\section{Palabras finales}

A partir del análisis de la trayectoria de Chaves en materia de interacción con individuos, colectivos e instituciones españolas desde que llegó a América hasta los años previos a su muerte, repasamos los hitos a partir de los cuales se construyó tanto una figura de poder peculiar como el perfil singular del conquistador del oriente boliviano.

Los hechos y personajes examinados nos permiten entender las acciones concretas y las opciones políticas de Chaves en el marco de la gobernación rioplatense como secuencia de estrategias desplegadas en pos de llegar a la tierra del Candire. Su incorporación al bando iralista en el contexto de la disputa con Cabeza de Vaca fue el puntapié inicial a partir del cual asumió un papel relevante en la exploración del río Paraguay y las tierras del Chaco. Producto de esas exploraciones tuvo lugar su arribo

\footnotetext{
${ }^{76}$ GGV 90/ 1388.5, Diez cartas de la Audiencia de Charcas al Rey, La Plata, 1561-1567.

${ }^{77}$ Juan Ortiz de Zárate era uno de los hombres más influyentes de Charcas. Había sido recompensado por La Gasca en 1548 con una encomienda que involucraba indios carangas de Totora, Lipez, los valles de Tarija y Chichas. Concentró sus actividades económicas en Potosí y La Plata, gracias a las cuales se volvió para el licenciado Matienzo, oidor de la Audiencia de Charcas, el hombre indicado para llevar adelante el proyecto de exploración de las tierras rioplatenses comunicando a Charcas con la vía atlántica (Presta, 2000: 175).
} 
-junto con Irala y su hueste- al confín de Charcas. El papel de embajador del Río de la Plata ante el gobernador del Perú, Pedro de La Gasca, resultó ser, por un lado, el indicador de la sociedad con Domingo Martínez de Irala y, por otra parte, una experiencia de peso para la consolidación de su liderazgo en la relación con las autoridades virreinales $-\mathrm{y}$, no menos importante, con la hueste que engrosó con la incorporación hombres peruanos al espacio paraguayo. El arribo de Hernando de Salazar a principios de la década del '50 multiplicó las posibilidades de sostener negociaciones fructíferas con los centros de poder virreinal y con los soldados que los acompañaban, así como de enfrentarse a eventuales adversarios. Las mediaciones de Salazar, aunque no siempre de resultado favorable, dejaron un balance ampliamente positivo: el revés sufrido por la división de la hueste en pleno territorio chiquitano fue contrarrestado con el triunfo sobre Manso y por la provisión de títulos para la gobernación de Mojos.

A las mismas conclusiones llegamos al sopesar los factores que motorizaron la conquista con aquellos otros que le pusieron freno u obstáculos. Las negativas de Pedro de Orantes a la realización de entradas de exploración y conquista por parte de Irala y Chaves a la larga no torcieron el destino transchaqueño de éste último, pero indicaron el opuesto de la política expansiva con la que identificamos al protagonista de nuestra historia. En contraste con lo que durante esos mismos años ocurría en el Perú, donde se alentaba la realización de nuevas entradas para descomprimir la ocupación de la tierra, en el espacio marginal de la gobernación del Río de la Plata la ejecución de nuevas expediciones implicaba poner en riesgo el delicado equilibrio de las relaciones con los nativos, comprometer las posibilidades de subsistencia de los pobladores de Asunción y relegar a un segundo plano la comunicación con la metrópoli de un espacio que contaba con altos niveles de aislamiento desde la despoblación de Buenos Aires.

Una mención aparte merece el enfrentamiento de Ñuflo de Chaves con Andrés Manso, paradigmático de la condición mediterránea del área cruceña en relación con los núcleos de colonización española del Perú y el Río de la Plata. Además, paradójicamente, este episodio representó un obstáculo en pos de cuya resolución se pusieron en juego los conocimientos y ventajas que Chaves llevaba acumulados durante su trayectoria: la lealtad de la hueste, las dotes diplomáticas de Hernando de Salazar, la experiencia previa de la embajada en la Ciudad de los Reyes.

Por su parte, la posición de la Audiencia de Charcas en relación con este conflicto pudo haber resultado ambigua y muchas veces contraria a los intereses de Chaves. Pero como sostuvimos en los últimos párrafos, se trató de una estrategia que lejos de ser errática atendía efectivamente los intereses de los propios vecinos de La Plata y las necesidades del centro de la economía colonial peruana: Potosí. Al final, la integración de la gobernación de Chaves a ese proyecto le permitió contar con el apoyo de aquella institución colonial charqueña. El costo no fue menor para las aspiraciones iniciales de los españoles llegados desde Asunción: el sueño de llegar a El Dorado sería relegado a un segundo plano frente a las demandas de Charcas, que los nuevos pobladores de los llanos del oriente estuvieron llamados a satisfacer. 


\section{Bibliografía}

\section{Documentos citados}

En repositorios documentales

GGV: Colección Gaspar García Viñas de la Biblioteca Nacional de Buenos Aires. La barra separa número de tomo de número de documento.

En series documentales publicadas

Covarrubias, Sebastián de. 1943 [1611]. Tesoro de la lengua castellana o española, Barcelona, S. A. Horta.

Díaz de Guzmán, Ruy. 1910 [1612] "La Argentina” en De Angelis, Pedro. 1910. Colección de obras y documentos relativos a la historia antigua y moderna de las provincias del Río de la Plata, Buenos Aires, Librería Nacional de J. Lajovane y Cia. Editores.

Julien, Catherine. 2008. Desde el oriente. Documentos para la historia del Oriente Boliviano y Santa Cruz la Vieja, Santa Cruz de la Sierra, Fondo Editorial Municipal.

Levillier, Roberto. 1915. Correspondencia de los Oficiales Reales de hacienda del Río de la Plata con los Reyes de España. Tomo 1 1540-1596, Madrid, Sucesores de Rivadeneyra.

Levillier, Roberto. 1921. Gobernantes del Perú. Cartas y papeles. Siglo XVI.Documentos del Archivo de Indias, Madrid, Imprenta de Juan Pueyo.

Levillier, Roberto. 1922. Audiencia de Charcas. Correspondencia de presidentes y oidores, Documentos del Archivo de Indias, Madrid, Imprenta de Juan Pueyro.

Maúrtua, Víctor M. 1906. Juicio de límites entre el Perú y Bolivia, Tomo Noveno Mojos I. Madrid, Imprenta de los hijos de M. G. Hernández.

En apéndices documentales de obras contemporáneas

Irala, Domingo Martínez de. 1964 [1555] "Carta de Domingo Martínez de Irala al Consejo de Indias, refiriendo sus entradas y descubrimientos por el río Paraguay hasta el Perú y lo ocurrido en aquellas expediciones y en los asientos del Río de la Plata. Ciudad de Asunción, 24 de julio de 1555”. En Lafaye, Jacques. 1962. Los conquistadores, México, Fondo de Cultura Económica, pp. 276-282.

\section{Obras contemporáneas}

Assadourian, Carlos Sempat. 1982. El sistema de la economía colonial. Mercado interno, regiones y espacio económico, Lima, Instituto de Estudios Peruanos.

Coello de la Rosa, Alexandre. 2007. "Los jesuitas y las misiones de frontera del alto Perú: Santa Cruz de la Sierra (1587-1603)"'. En: Revista Complutense de Historia de América, No 33, Madrid, Universidad Complutense. pp. 151-175.

Combés, Isabelle. 2005. Etnohistorias del Isoso. Chané y chiriguanos en el Chaco boliviano (siglos XVI a XX), La Paz, Fundación Pieb / IFEA. 
Combés, Isabelle. 2010 Diccionario étnico Santa Cruz la Vieja y su entorno en el siglo XVI, Cochabamba, Instituto de Misionología.

Combès, Isabelle. 2011 "El Paititi, los candires y las migraciones guaraníes". En: Suplemento Antropológico XVVI No 1, Asunción del Paraguay, pp. 7-149

Combès, Isabelle y Vera Tyuleneva (eds.). 2011 Paititi. Ensayos y documentos, Cochabamba, Instituto de Misionología / Editorial Itinierarios.

Elliott, John H. 1983 [1963]. La España Imperial. 1469-1716, Barcelona, Vicens-Vives. Finot, Enrique. 1939. Historia de la conquista del Oriente Boliviano, Buenos Aires: Librería Cervantes.

García Recio, José María. 1988. Análisis de una sociedad de frontera. Santa Cruz de la Sierra en los siglos XVI y XVII. Sevilla, Publicaciones de la Excelentísima Diputación Provincial de Sevilla.

Gandía, Enrique de. 1932. Historia de la conquista del Río de la Plata y del Paraguay. Los gobiernos de Don Pedro de Mendoza y Domingo de Irala. 1535-1556, Buenos Aires, Librería de A. García Santos.

Gandía, Enrique de. 1935. Historia de Santa Cruz de la Sierra. Una nueva república en Sud América, Buenos Aires, Talleres Gráficos Argentinos de L.J. Rosso.

Levillier, Roberto. 1976. El Paititi, el Dorado y las Amazonas, Buenos Aires, Emecé.

Métraux, Alfred. 1942. The native tribes of Eastern Bolivia and Western Matto Grosso, Washington, Bureau of American Ethnology Bulletin 134.

Presta, Ana María. 1997. "Encomienda, familia y redes en Charcas colonial: los Almendras, 1540-1600". En: Revista de Indias, Vol. LVII N ${ }^{\circ}$ 209, Madrid, Instituto de Historia (CSIC), pp. 21-53.

Presta, Ana María. 2000. Encomienda, familia y negocios en Charcas colonial (Bolivia): los Encomenderos de La Plata 1550-1600, Lima, IEP/BCRP.

Roulet, Florencia. 1993. La resistencia de los guarani del Paraguay a la conquista española (1537-1556), Posadas, Editorial Universitaria - Universidad Nacional de Misiones.

Sanabria, Hernando. 1984 [1968]. Ñuflo de Chaves. El caballero andante de la selva, La Paz, Librería Editorial "Juventud".

Saignes, Thierry. 1985. Los Andes Orientales: Historia de un olvido, Cochabamba, CERES.

Saignes, Thierry. 2007. Historia del pueblo chiriguano, La Paz, Instituto Francés de Estudios Andinos / Embajada de Francia en Bolivia / Plural editores.

Stern, Steve. 1992. "Paradigmas de la conquista: historia, historiografía y política". En Boletín del Instituto de Historia Argentina y Americana "Dr. Emilio Ravignani". Tercera serie, $\mathrm{N}^{\mathrm{o}}$ 6, Buenos Aires, pp. 7-40.

Susnik, Branislava. 1968. Chiriguanos I. Dimensiones etnosociales, Asunción, Museo Etnográfico Andrés Barbero.

Susnik Branislava. 1978. Los aborígenes del Paraguay I. Etnología del Chaco Boreal y su periferia (siglos XVI y XVIII), Asunción, Museo Etnográfico Andrés Barbero. 